\title{
A Bibliometric Analysis of Social Media Research from the Perspective of Library and Information Science
}

\author{
Chunmei Gan ${ }^{1, *}$ and Weijun Wang ${ }^{2}$ \\ ${ }^{1}$ School of Information Management, Sun Yat-sen University, Guangzhou, China \\ chunmei_gan@163.com \\ ${ }^{2}$ School of Information Management, Central China Normal University, Wuhan, China \\ wangwj@mail.ccnu.edu.cn
}

\begin{abstract}
A bibliometric analysis was conducted on social media research in journals under the subject category "Information Science \& Library Science" of the Social Science Citation Index. 646 articles were retrieved using the term "social media" as a keyword to search parts of titles, abstracts or keywords of publications. The research performance and trends were analyzed with descriptors of types and languages, characteristics, countries, journals, authorships and author keywords. Results showed that, social media research steadily increased from the period of 2002 to 2013 and the annual publication output in 2012 and 2013 were almost half of the total. A total of 9,851 pages, 29,433 cited references, 1,540 authors and 3,740 citations were identified in all 646 articles, with the average per article of 15.25 pages, 45.46 cited references, 2.38 authors and 5.79 citations. Analysis of countries and journals suggested an uneven distribution of publications on national and journal levels. The USA attained a leading position by contributing the largest share of articles. UK, Spain and China were the other three top productive countries in total publications. $73.53 \%$ of the total articles were published in 25 journals with impact factors ranging from 0 to 5 . More than half (51.24\%) journals had an impact factor between 1 and 3. Journal of Health Communication with $2.079 \mathrm{IF}$ had published the most articles. The most commonly used author keywords appeared in the articles were "social media", "social network", "Internet", "communication", "Web 2.0", "blog", "Twitter", "Facebook" and "virtual community".
\end{abstract}

Keywords: Social media, bibliometric, SSCI, research performance, trends.

\section{Introduction}

Social media develops rapidly over the past years, and plays an increasingly important role in a variety of fields, such as business, education and daily life for organizations or individuals. There is a growing consensus that social media is fundamentally changing the way individuals communicate, consume and collaborate [1]. Recent reports show that, $65 \%$ of Australians use social media [2], while $43.8 \%$ of Internet users use social media in China [3].Also, $73 \%$ of online American adults use a social

* Corresponding author.

H. Li et al. (Eds.): I3E 2014, IFIP AICT 445, pp. 23-32, 2014.

(C) IFIP International Federation for Information Processing 2014 
networking site of some kind [4]. In addition, reports reveals that, marketers place very high value on social media, a significant $86 \%$ of marketers indicate that social media is important for their business [5].

Social media research has experienced a considerable increase due to the mentioned popular use of social media technologies and their impacts. Great efforts have been made around the world to better understand and utilize social media. A number of reviews were published within the social media research fields (e.g. $[1,6-8])$. However, there were no attempts to provide a more quantitative assessment of the current status and trends of this research thus far.

Scientometrics that measuring the contribution of scientific publications within a given topic could represent current research trends and be used to identify focuses of future. It uses statistical and mathematical tools to map out data and patterns of bibliographical records pertaining to a network of scientific documents. Through bibliometric research of literature, the next research trend could be predicted [9]. Bibliometric studies that evaluate status and progresses of a specific topic based on publication records have a long research strand and have been applied to evaluate performance of publications in many areas.

The purpose of the present research, through a comprehensive bibliometric analysis, is to analyze the status and trends of social media research from the perspective of Library and Information Science (LIS) until the year of 2013, so as to help researchers better understand the panorama of global social media research and predict dynamic direction of research.

\section{Research Methods}

The data used in this study was obtained from the database of SSCI published by Thomson Reuters Web of Science, Philadelphia, PA, USA. As a strictly selected abstract database, Web of Science has been long recognized as the most authoritative scientific and technical literature indexing tool that can provide the most important areas of science and technology research [10]. To retrieve papers dealing with social media research in LIS discipline, the term "social media" was used as a search query phrase to search the titles, abstracts and keywords of referenced publications under the category of "Information Science \& Library Science". A total of 768 publications were identified in the SSCI databases for the period 2002-2013.

In addition, the impact factor (IF) of a journal was determined for each document as reported in the year 2012 by ISI's Journal Citation Reports (JCR). Citation counts of all the papers obtained on March 10th, 2014 when the SSCI search process for this study was conducted. And publications originating from England, Scotland, North Ireland and Wales were grouped under the UK (United Kingdom) heading.

We then performed a bibliometric analysis based on the following descriptors: types and languages of publications, characteristics of scientific output, publication distribution by countries, distribution of outputs in journals, authorships as well as frequencies of author keywords, so as to study the worldwide research activity on social media from the perspective of LIS in general and determine the research trends and performance. The statistical analysis was conducted by the combined use of BibExcel [11] and MS Excel. Also, for analysis of author keywords, following the 
formation of the basic word list, all words devoid of meaning (i.e., "if", "and", "with", etc.) were removed from the list, and the alternate forms of words were grouped together.

\section{Results and Discussion}

\subsection{Types and Languages of Publications}

There were 768 papers on social media research under category of LIS in the ISI Web of Science database. 6 document types were identified. The most frequent document type was journal articles (646), comprising $84.11 \%$ of the total publication, followed by book review $(50,6.51 \%)$ and editorial material $(43,5.6 \%)$. Other less significant document types were review $(27,3.52 \%)$, proceedings paper $(25,3.26 \%)$ and news item $(2,0.26 \%)$, which accounted for $7.03 \%$ in total.

Since original articles were the most-frequently used type, also following the conventions used in other bibliometric studies, journal articles were used for further analysis, while other types of publications were then removed.

As for publishing language, English remains the dominant language, making up $92.41 \%$ (597) of all the published articles. This result was consistent with the fact that English is the prevalent academic language as most journals indexed by SSCI are published in English. Other publication languages included Spanish (34), Hungarian (7), Portuguese (4), German (3) and French (1).

\subsection{Characteristics of Scientific Output}

The articles devoted to social media research from the perspective of LIS were summarized in Table 1, showing some basic characteristics of all 646 articles. The number of total pages (NP) for all 646 articles was 9,851, and the average page per article (NP/NA) was 15.25. Further, among the 646 articles, the maximum pages were 52 , and the minimum was 1 . The article with 52 pages was "researchers and practitioners talk about users and each other: making user and audience studies matter", written by Dervin B and Reinhard C D, and published in "Information Research - An international electronic journal". Both of the two articles with 1 page were published in "Econtent" journal, written by Scott D M in 2007 and 2009, and titled with "social media debate" and "after thought armed with social media", respectively.

Table 1. Characteristics of articles outputs

\begin{tabular}{|l|c|c|c|c|c|c|c|c|c|}
\hline & NA & NP & NP/NA & NR & NR/NA & NAU & NAU/NA & TC & TC/NA \\
\hline Total & 646 & 9,851 & 15.25 & 29,433 & 45.56 & 1,540 & 2.38 & 3,740 & 5.79 \\
\hline Max & $/$ & 52 & $/$ & 160 & $/$ & 17 & $/$ & 139 & $/$ \\
\hline Min & $/$ & 1 & $/$ & 0 & $/$ & 1 & $/$ & 0 & $/$ \\
\hline
\end{tabular}

Note: NA number of total articles, NP number of total pages, NP/NA average page per article, NR number of cited references, NR/NA average cited references per article, NAU number of total authors, NAU/NA average author per article, TC times cited, TC/NA times cited per article, Max The maximum, Min The minimum, / no data 
The total number of cited references (NR) for all 646 articles was 29,433, and the average cited references per article (NR/NA) were 45.46. In addition, the maximum cited reference was 160 , while the minimum was 0 . The article with 160 cited references was titled "online social movements", a review paper published in "Annual Review of Information Science and Technology" journal in 2011, written by Hara N and Huang B Y from Indiana University. Also, there were 15 articles with 0 cited references. The further analysis of these 15 articles revealed that their topics were intensively related to social media applications in different areas, such as business, marketing and library. Meanwhile, 8, 5, 1 and 1 article(s) were published in journals "Econtent", "Online", "Learned Publishing" and "Profesional de la Información", respectively.

For authors, there were 1,540 authors in total (NAU) for all 646 articles, and the number of average authors per article (NAU/NA) was 2.38, indicating the collaboration trend for current research. Moreover, the article with the most authors was written by 17 authors, of which 6 from Korea and 11 from Pakistan, and published in "Journal of Health Communication".

Additionally, there were 3,740 citations (TC) in the total of 646 publications for an average of 5.79 citations per article (TC/NA), indicating the high impact or visibility of social media research from LIS. The most frequently cited article was "acceptance of Internet-based learning medium: the role of extrinsic and intrinsic motivation", written by Lee M K O, Cheung C M K and Chen Z from Hong Kong, China. This article was published in "Information \& Management" journal, and empirically investigated extrinsic and intrinsic motivators affecting students' intention to use an Internet -based learning medium. It has been cited 139 times since published in 2005. Meanwhile, among the most times cited articles, 129 (19.97\%) articles were cited by $2,970(79.41 \%)$ times, following the Pareto principle.

In addition, Figure 1 shows the publication years of all 646 articles. We could find that research on social media has risen yearly from 2003 to 2013 and aroused more and more attention in recent years. The annual number of publication output has grown rapidly from 16 in 2002 to 174 in 2013. Articles published in the year of 2012 and 2013 accounted for almost half of the total publications (45.2\%).

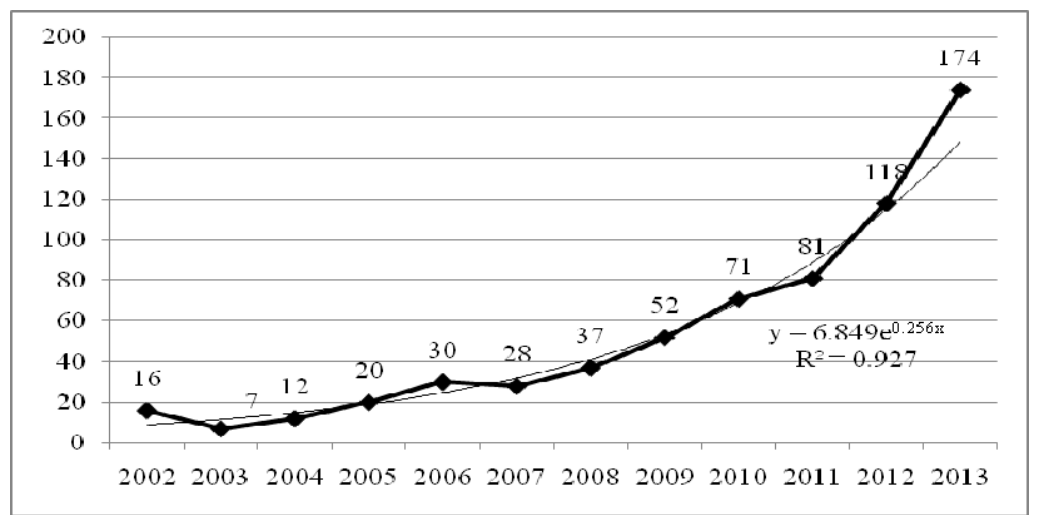

Fig. 1. Publications of each year 
Also, as shown in Fig. 1, the progression in the number of articles each year was further studied. There were significant correlations between the publication years and the number of articles published in those years. The growth pattern of the progression was simulated by one exponential function $y=6.849 \mathrm{e}^{0.256 \mathrm{x}}$, with coefficients of determination $\mathrm{R}^{2}=0.927$.

\subsection{Publication Distribution by Countries}

LIS scholars from 54 countries have contributed in social media research. Table 2 presented the top 15 countries/territories that were most productive, suggesting a geographic inequality. Among 17 countries/territories ranked top 15, there were 9 European countries, 5 Asian countries, 2 and 1 from North America and Africa, respectively. Moreover, USA ranked first with 297 (39.23\%) publications, followed by UK $(63,8.32 \%)$ and Spain $(49,6.47 \%)$. China $(38,5.02 \%)$ ranked the fourth in total publications.

Table 2. Top 15 countries/territories with most articles

\begin{tabular}{|l|c|c|l|l|c|c|l|}
\hline Country & Articles & Percentage\% & $\begin{array}{l}\text { Country } \\
\text { by region }\end{array}$ & Country & Articles & Percentage\% & $\begin{array}{l}\text { Country } \\
\text { by region }\end{array}$ \\
\hline USA & 297 & $39.23 \%$ & $\begin{array}{l}\text { North } \\
\text { America }\end{array}$ & Finland & 15 & $1.98 \%$ & Europe \\
\hline UK & 63 & $8.32 \%$ & Europe & Sweden & 15 & $1.98 \%$ & Europe \\
\hline Spain & 49 & $6.47 \%$ & Europe & Singapore & 14 & $1.85 \%$ & Asia \\
\hline China & 38 & $5.02 \%$ & Asia & Israel & 13 & $1.72 \%$ & Asia \\
\hline Canada & 33 & $4.36 \%$ & $\begin{array}{l}\text { North } \\
\text { America }\end{array}$ & $\begin{array}{l}\text { South } \\
\text { Africa }\end{array}$ & 9 & $1.19 \%$ & Africa \\
\hline South Korea & 29 & $3.83 \%$ & Asia & Ireland & 8 & $1.06 \%$ & Europe \\
\hline Netherlands & 24 & $3.17 \%$ & Europe & Italy & 8 & $1.06 \%$ & Europe \\
\hline Australia & 23 & $3.04 \%$ & Europe & Taiwan & 8 & $1.06 \%$ & Asia \\
\hline Germany & 21 & $2.77 \%$ & Europe & Total & 667 & $88.11 \%$ & $/$ \\
\hline
\end{tabular}

\subsection{Distribution of Output in Journals}

All 646 articles were published in a wide range of 78 journals. Table 3 lists the top 16 journals (25 journals in total) with the greatest number of published articles, comprising $73.53 \%$ of the total 646 articles. There was a high concentration of social media publications in these top journals, which follows the Zipf's law and is consistent with observation in other fields. Journal of Health Communication ranked first with 55 published articles, followed by Journal of Computer-Mediated Communication with 50 published articles.

Impact factor and journal rank of each journal are also shown in Table 3. Impact factors of all the 25 journals were ranged from 0 to 5 according to 2012 JCR Social Science Edition. The journal with the highest impact factor was MIS Quarterly (4.659, ranked $1^{\text {st }}$ of 85 journals in LIS) with 8 published articles, followed by Scientometrics $\left(2.133\right.$, ranked $\left.7^{\text {th }}\right)$ and Journal of Health Communication $\left(2.079\right.$, ranked $\left.8^{\text {th }}\right)$. 
Table 3. The top 16 journals with the greatest number of articles

\begin{tabular}{|c|c|c|c|c|}
\hline Journal & $\mathrm{P}$ & $\mathrm{P} \%$ & IF & Journal rank \\
\hline Journal of Health Communication & 55 & $8.51 \%$ & 2.079 & $8 / 85$ \\
\hline Journal of Computer-Mediated Communication & 50 & $7.74 \%$ & 1.778 & $13 / 85$ \\
\hline Government Information Quarterly & 39 & $6.04 \%$ & 1.910 & $11 / 85$ \\
\hline Social Science Computer Review & 37 & $5.73 \%$ & 1.303 & $24 / 85$ \\
\hline $\begin{array}{c}\text { Journal of the American Society for Information } \\
\text { Science and Technology }\end{array}$ & 32 & $4.95 \%$ & 2.005 & $10 / 85$ \\
\hline Profesional de la Información (Spanish) & 29 & $4.49 \%$ & 0.439 & $53 / 85$ \\
\hline Information Society & 28 & $4.33 \%$ & 1.114 & $30 / 85$ \\
\hline Information Systems Research & 20 & $3.10 \%$ & 2.010 & $9 / 85$ \\
\hline Aslib Proceedings & 19 & $2.94 \%$ & 0.432 & $54 / 85$ \\
\hline Telematics and Informatics & 16 & $2.48 \%$ & I & I \\
\hline Journal of Documentation & 15 & $2.32 \%$ & 1.138 & $29 / 85$ \\
\hline Online Information Review & 13 & $2.01 \%$ & 0.939 & $37 / 85$ \\
\hline $\begin{array}{c}\text { Information Research - An International } \\
\text { Electronic Journal }\end{array}$ & 11 & $1.70 \%$ & 0.520 & $49 / 85$ \\
\hline Library Hi Tech & 11 & $1.70 \%$ & 0.621 & $46 / 85$ \\
\hline Libri & 10 & $1.55 \%$ & 0.368 & $64 / 85$ \\
\hline Journal of Information Science & 10 & $1.55 \%$ & 1.238 & $26 / 85$ \\
\hline Scientometrics & 10 & $1.55 \%$ & 2.133 & $7 / 85$ \\
\hline Information \& Management & 10 & $1.55 \%$ & 1.663 & $15 / 85$ \\
\hline Electronic Library & 10 & $1.55 \%$ & 0.667 & $44 / 85$ \\
\hline Ethics and Information Technology & 9 & $1.39 \%$ & 0.846 & $40 / 85$ \\
\hline $\begin{array}{c}\text { International Journal of Information } \\
\text { Management }\end{array}$ & 9 & $1.39 \%$ & 1.843 & $12 / 85$ \\
\hline Journal of Knowledge Management & 8 & $1.24 \%$ & 1.474 & $20 / 85$ \\
\hline MIS Quarterly & 8 & $1.24 \%$ & 4.659 & $1 / 85$ \\
\hline Econtent & 8 & $1.24 \%$ & 0.127 & $79 / 85$ \\
\hline Journal of Management Information Systems & 8 & $1.24 \%$ & 1.262 & $25 / 85$ \\
\hline
\end{tabular}

Shares of articles in different ranges of impact factor were further analyzed (Table 4). There were 9 journals with impact factor between 0 and 1, 10 journals between 1 and 2, 4 journals between 2 and 3, and 1 journal between 4 and 5 . In addition, journals with impact factor between 1 and 3 accounted for more than half $(51.24 \%)$ of the total publications, which indicated that qualities of publications in social media research from LIS scholars were high. 
Table 4. Shares of publications in different ranges of impact factor

\begin{tabular}{|r|c|c|c|c|c|c|c|}
\hline $\mathrm{IF}$ & $\mathrm{J}$ & $\mathrm{P}$ & $\mathrm{P} \%$ & $\mathrm{IF}$ & $\mathrm{J}$ & $\mathrm{P}$ & $\mathrm{P} \%$ \\
\hline $0<\mathrm{IF} \leqq 1$ & 9 & 120 & 18.58 & $3<\mathrm{IF} \leqq 4$ & 0 & 0 & 0 \\
\hline $1<\mathrm{IF} \leqq 2$ & 10 & 214 & 33.13 & $4<\mathrm{IF} \leqq 5$ & 1 & 8 & 1.24 \\
\hline $2<\mathrm{IF} \leqq 3$ & 4 & 117 & 18.11 & N/A & 1 & 16 & 2.48 \\
\hline Total & 25 & 475 & 73.53 & \multicolumn{5}{|l}{} \\
\hline
\end{tabular}

Note: IF impact factor, J number of journals, $\mathrm{P}$ total publications, $\mathrm{P} \%$ share in publications, N/A no data

\subsection{Patterns of Authorships}

There were 201 articles with single author, while 445 articles with multiple authors. Moreover, 1,448 authors appearing 1,540 times were identified for all the 646 articles. 67 authors published at least 2 articles, and 1,381 author published one article. Table 5 lists frequency of times authors appeared of the total publications.

Table 5. Frequency of times authors appeared

\begin{tabular}{|c|c|c|c|c|c|c|c|c|}
\hline $\mathrm{T}$ & $\mathrm{F}$ & $\mathrm{F} \%$ & $\mathrm{~T}$ & $\mathrm{~F}$ & $\mathrm{~F} \%$ & $\mathrm{~T}$ & $\mathrm{~F}$ & $\mathrm{~F} \%$ \\
\hline 9 & 1 & 0.07 & 4 & 3 & 0.21 & 2 & 54 & 3.73 \\
\hline 6 & 1 & 0.07 & 3 & 8 & 0.55 & 1 & 1381 & 95.37 \\
\hline
\end{tabular}

Total: 1448

Note: T Times appeared, F frequency, F\% share of frequency

We also list the most productive authors published at least 4 articles in Table 6. The most productive author in social media research from LIS was Park H W (12 articles) from Yeungnam University in South Korea, followed by Bonson E (6 articles) from University of Huelva in Spain, Rice R E (5 articles) from University of California, Santa Barbara in USA and Thelwall M (5 articles) from University of Wolverhampton in UK.

Table 6. The most productive authors

\begin{tabular}{|c|c|c|c|c|c|}
\hline Author name & Articles & Author name & Articles & Author name & Articles \\
\hline Park HW & 12 & Flores F & 4 & Marcella R & 4 \\
\hline Bonson E & 6 & Yuan YC & 4 & Bertot JC & 4 \\
\hline Rice RE & 5 & Jaeger PT & 4 & \multirow{2}{*}{ Total } & 52 \\
\hline Thelwall M & 5 & Baxter G & 4 & \\
\hline
\end{tabular}

\subsection{Frequencies of Author Keywords}

The technique of statistical analysis of keywords may reflect directions of research. Especially, authors' keywords analysis could offer the information of research trends as viewed by researchers [9]. Examination of author keywords revealed that, 1,649 
keywords were identified among the total 646 publications. Table 7 shows the frequency of different number of keywords appeared in different times. Among them, 1,386 (84.05\%) keywords appeared only once, and $147(8.91 \%)$ appeared twice. These words maybe reflected a lack of continuity in research and a wide difference in research focuses [12].

Table 7. Frequency of keywords appeared in different times

\begin{tabular}{|c|c|c|c|c|c|c|c|c|}
\hline $\begin{array}{c}\text { Times } \\
\text { appeared }\end{array}$ & $\begin{array}{c}\text { Number } \\
\text { of key- } \\
\text { words }\end{array}$ & $\begin{array}{c}\text { Frequency } \\
\%\end{array}$ & $\begin{array}{c}\text { Times } \\
\text { appeared }\end{array}$ & $\begin{array}{c}\text { Number } \\
\text { of key- } \\
\text { words }\end{array}$ & $\begin{array}{c}\text { Frequency } \\
\%\end{array}$ & $\begin{array}{c}\text { Times } \\
\text { appeared }\end{array}$ & $\begin{array}{c}\text { Number } \\
\text { of key- } \\
\text { words }\end{array}$ & $\begin{array}{c}\text { Frequency } \\
\%\end{array}$ \\
\hline 1 & 1,386 & 84.05 & 9 & 2 & 0.12 & 21 & 2 & 0.12 \\
\hline 2 & 147 & 8.91 & 10 & 3 & 0.18 & 22 & 1 & 0.06 \\
\hline 3 & 55 & 3.34 & 12 & 1 & 0.06 & 23 & 1 & 0.06 \\
\hline 4 & 18 & 1.09 & 13 & 2 & 0.12 & 35 & 1 & 0.06 \\
\hline 5 & 9 & 0.55 & 14 & 1 & 0.06 & 38 & 1 & 0.06 \\
\hline 6 & 6 & 0.36 & 15 & 1 & 0.06 & 45 & 1 & 0.06 \\
\hline 7 & 2 & 0.12 & 18 & 1 & 0.06 & 69 & 1 & 0.06 \\
\hline 8 & 5 & 0.30 & 19 & 1 & 0.06 & 142 & 1 & 0.06 \\
\hline
\end{tabular}

We also presented the top 15 most active author keywords in Table 8. Other than the term "social media" used for searching, the most frequently used keywords was "social network", which is highly accorded with that fact that social network has attracted much attention from scholars. Also, "Internet" and "communication" were the other two most active words. This is consistent with the fact that social media is a type of new Internet application and is convenient for people to communicate with each other. In addition, "Web 2.0", "blog", "Twitter", "Facebook" and "virtual community" were paid more attention to because they are typical applications of social media and used mostly according to the current statistic reports. Furthermore, social media is applied into different areas, as "library" (21), "political participation" (13) and "e-government" (12) were also appeared in the list.

Table 8. Top 15 most active author keywords

\begin{tabular}{|c|c|c|c|c|c|}
\hline Author keyword & Times & Author keyword & Times & Author keyword & Times \\
\hline social media & 142 & Facebook & 21 & political participation & 13 \\
\hline social network & 69 & library & 21 & e-government & 12 \\
\hline Internet & 45 & virtual community & 19 & Information retrieval & 10 \\
\hline communication & 38 & social interaction & 18 & knowledge management & 10 \\
\hline Web 2.0 & 35 & social capital & 15 & innovation & 10 \\
\hline Blog & 23 & $\begin{array}{c}\text { social network } \\
\text { analysis }\end{array}$ & 14 & Total & 550 \\
\hline Twitter & 22 & digital divide & 13 & & \\
\hline
\end{tabular}




\section{Conclusion}

In this study, we provided a supplement evaluation on the global research status and trends in social media studies from the perspective of LIS, utilizing scientometrics approach by summarizing types and languages, characteristics, geographic distributions, journals, patterns of authorships and frequencies of author keywords. The findings of this study could help LIS researchers better understand the performance of social media research in the world, as well as direct for future research.

The study showed that social media research in LIS started in 2002 and has a steady growth in the scientific outputs, following one exponential function in terms of increasing number of annual publications. Also, publications of the year of 2012 and 2013 accounted for almost half of the total publications (45.2\%), suggesting social media research has attracted increasing interests from LIS scholars in recent years.

There were 768 papers related to social media research under category of LIS, of which 6 document types were identified and journal articles made up of the majority (84.11\%). All 646 articles had a total of 9,851 pages, 29,433 cited references and 1,540 authors. The average for one article was 15.25 pages, 45.46 cited references and 2.38 authors. Meanwhile, all articles got 3,740 citations with an average of 5.79 citations per article. And 129 (19.97\%) articles were cited by 2970 (79.41\%) times, which follows the Pareto principle.

The research output distributed unevenly over 54 countries contributed in social media research. The USA attained a leading position by contributing the largest share of articles. UK, Spain and China were the other three top productive countries in total publications.

All 646 articles were published in 78 journals, of which $73.53 \%$ were published in top 16 journals with impact factors ranging from 0 to 5, and followed the Zipf's law. The journal with the most published articles was Journal of Health Communication with $2.079 \mathrm{IF}$, ranking 8th of 85 journals in LIS. Also, MIS Quarterly and Scientometrics were the top 2 journals with the highest IF among the top 16 journals. Also, more than half (51.24\%) journals had an impact factor between 1 and 3 .

201 articles were written by single author and 445 articles by multiple authors. 1,448 authors were identified with 1,540 times appeared, of which 67 authors published at least 2 articles and 1,381 author published one. The most productive author was Park H W (12 articles), Bonson E (6 articles), Rice R E (5 articles) and Thelwall $\mathrm{M}$ (5 articles).

1,649 keywords were presented among the total 646 publications, of which 1,386 $(84.05 \%)$ and $147(8.91 \%)$ keywords appeared only once and twice, respectively. The most commonly used author keywords appeared in the articles were "social media" and "social network", indicating that topics related to social network have received clearly increasing interests. In addition, "Internet", "communication", "Web 2.0", "blog", "Twitter", "Facebook" and "virtual community" were the most active author keywords, which reflected the current research focuses and might become the future research angles. 
Acknowledgements. This work was supported by National Natural Science Foundation of China (71073066 \& 71271099) and Central China Normal University (Program of excellent doctoral dissertation cultivation grant).

\section{References}

1. Wu, J.J., Sun, H.Y., Tan, Y.: Social media research: A review. Journal of Systems Science and Systems Engineering 22(3), 257-282 (2013)

2. Sensis. Yellow Pages Social Media Report (2013), http://about.sensis.com.au/IgnitionSuite/uploads/docs / Yellow\%2 0Pages\%20Social\%20Media\%20Report_F.PDF

3. The Kantar China Social Media Impact Report (2014), http: //cn.kantar.com/media/633232/2014.pdf

4. Social Media Update (2013), http: / / pewinternet.org/Reports / 2013 /Social-Media-Update. aspx

5. 2013 Social Media Marketing Industry Report, http: / /www. socialmediaexaminer.com/SocialMediaMarketingIndus tryReport2013.pdf

6. Bullard, S.B.: Writing on the Wall: Social Media-The First 2,000 Years. Journalism \& Mass Communication Quarterly 91(1), 182-183 (2014)

7. Gao, J.: Producing the Internet: Critical Perspective of Social Media. International Journal of Communication 8, 165-167 (2014)

8. Mesquita, A.: Social Media for Academics: A Practical Guide. Online Information Review 37(6), 987-988 (2013)

9. Garfield, E.: Citation Indexing for Studying Science. Nature 227(5259), 669-671 (1970)

10. Boyack, K.W., Klavans, R., et al.: Mapping the backbone of science. Scientometrics 64(3), 351-374 (2005)

11. Persson, O., Danell, R., Schneider, J.W.: How to use Bibexcel for various types of bibliometric analysis. In: Åström, F., Danell, R., Larsen, B., Schneider, J. (eds.) Celebrating scholarly communication studies: A Festschrift for Olle Persson at his 60th Birthday, pp. 9-24. International Society for Scientometrics and Informetrics, Leuven (2009)

12. Chuang, K.Y., Huang, Y.L., Ho, Y.S.: A bibliometric and citation analysis of strokerelated research in Taiwan. Scientometrics 72(2), 201-212 (2007) 